\title{
ANATOMICAL VARIATIONS OF THE TERMINAL BRANCHING OF THE BRACHIAL ARTERY
}

\author{
Abeywardhana $\mathrm{UN}^{1}$, Wahalawatte $\mathrm{YR}^{1}$, Dissanayake $\mathrm{JK}^{1}$, Amaratunga ${ }^{1}$ \\ 1 - Department of Anatomy, Faculty of Medicine, University of Peradeniya
}

\begin{abstract}
\section{Objective}

Knowledge regarding arterial variations is important during surgeries, intra-arterial injections, venipuncture and imaging of the upper limb. Our objective was to document brachial artery variations.
\end{abstract}

\section{Methods}

We studied 54 upper limb specimens during routine dissection. The anterior compartment of the arm, cubital fossa and the forearm were dissected and the pathway and the distribution of the brachial artery and its branches were documented.

\section{Results}

Variations of the brachial artery anatomy were noted in 3 specimens (5\%). Unilateral high bifurcation of brachial artery was noted in two specimens on the left side. In one of these, bifurcation was directly from the axillary artery at the axilla just proximal to the formation of the median nerve. Here the brachial artery divided into its terminal radial and ulnar branches. In the other specimen, the brachial artery bifurcated into radial and ulnar arteries at the level of the mid humerus. In the other specimen, the brachial artery was seen to trifurcate into radial, ulnar and common interosseus arteries at the level of the neck of the radius.

\section{Conclusions}

High brachial artery bifurcation and trifurcation of the brachial artery in the upper arm was noted in this study. Reporting of such variations in different populations is important for the practicing clinician during diagnostic and surgical procedures.

\section{Introduction}

Arterial distribution of the upper limb shows great anatomical variation [1]. Variations of the radial artery are the commonest followed by the ulnar artery and then the variations of the brachial artery [1]. Knowledge about the these anatomical variations is important during surgeries such as flap surgeries of forearm, amputations, fasciotomy for compartment syndromes and using radial artery for coronary artery bypass grafting as well as during intraarterial injections and venipuncture [2]. Further a thorough knowledge of the arterial anatomy prevents diagnostic error in imaging of limb vasculature [1].

Brachial artery is the continuation of the axillary artery beyond the lower boarder of the teres major muscle. It divides into the radial and ulnar arteries its terminal branches, opposite the neck of the radius in the anterior cubital region [4].

High bifurcation of the brachial artery is not a rare occurrence and accounts for $15 \%$ of the brachial artery variations [4]. It may bifurcate as high as the axillary artery, but most commonly it divides at the proximal $1 / 3$ of the upper arm [4]. Recent studies have revealed that the high bifurcation can cause several clinical implications including increased failure rate of AV fistulae created for hemodialysis [3]. 
High origin of ulnar artery is described as superficial ulnar artery where it arises as a branch of the axillary artery or from the brachial artery. Usually it lies superficial to the brachial artery and the median nerve. In the forearm it crosses the forearm flexors to the medial side of the arm [4]. Trifurcation of the brachial artery is relatively rare, where it trifurcates into the radial artery, ulnar artery, radial recurrent artery, common interosseous artery or into the median artery [5].

With this background, the study was designed to examine and document the variations of the terminal branching of the brachial artery.

\section{Methods}

The study was conducted on 54 upper limb specimens in 27 cadavers, 16 of which were male, during routine dissection at the Department of Anatomy, Faculty of Medicine, University of Peradeniya. The anterior compartment of the arm, cubital fossa and the forearm were dissected according to routine dissection procedures. The skin, superficial facia, deep facia and the muscles were dissected and separated. The brachial artery was carefully traced from its origin to it bifurcation. Observed anatomical variations of the terminal branching of the brachial artery were examined, documented and photographed.

\section{Results}

Variations of the branching of the brachial artery were noted in 4 specimens (5.5\%). Unilateral high bifurcation of brachial artery was noted in 2 cadavers (3.7\%). The bifurcation into radial and ulnar arteries was directly from the axillary artery in the axilla, just proximal to the formation of the median nerve in one cadaver (figure 1).

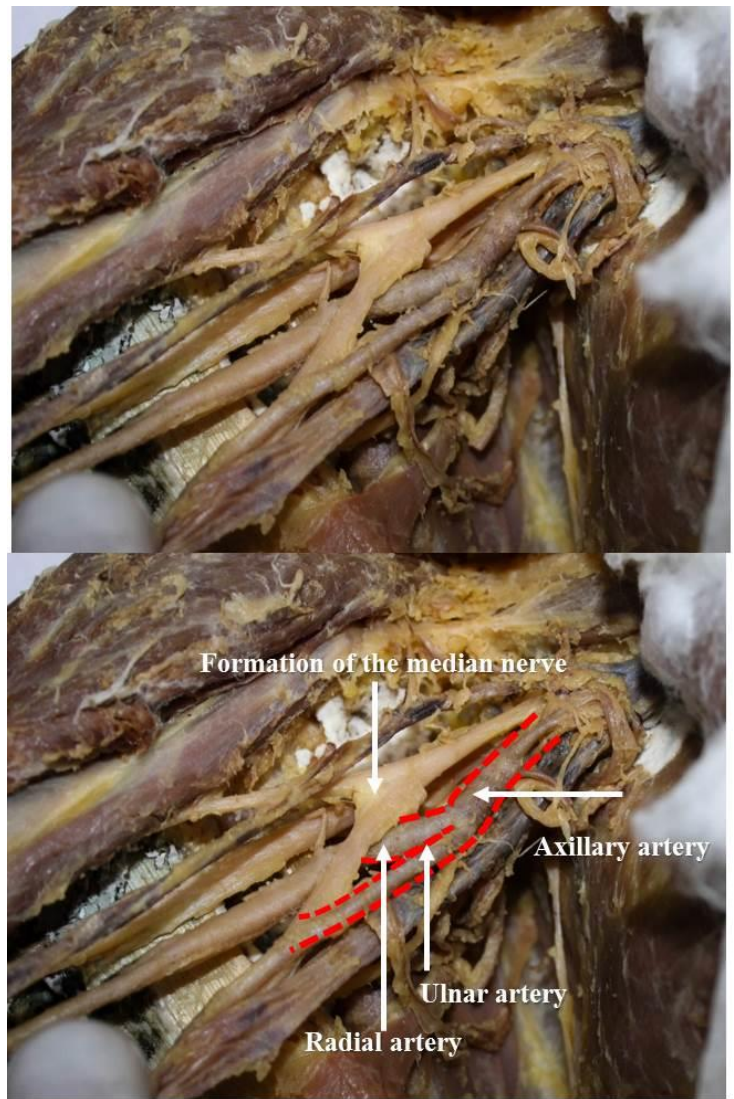

Figure 1: High bifurcation of the brachial artery

Thereafter both the branches were seen to travel in the anterior compartment of the arm to the cubital fossa and followed their normal course for the rest of their lengths. In the other cadaver brachial artery was seen to bifurcate into radial and ulnar arteries at the level of the mid humerus (figure 2).

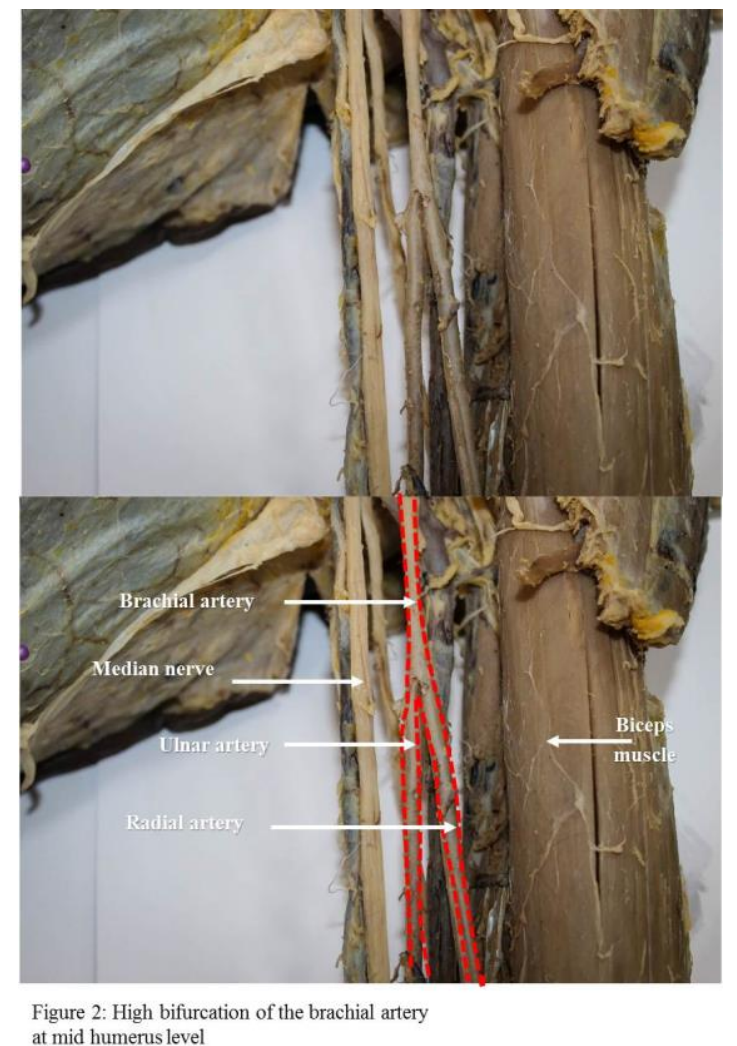


After the bifurcation, the radial and ulnar arteries continued in their normal course. Ulnar artery was seen to disappear deep into the deep head of pronator teres and ran medially and distally on flexor digitorum profundus. The radial artery passed distally and medial to the biceps tendon.

Unilateral trifurcation of brachial artery was noted in one cadaver $(1.85 \%)$. The brachial artery trifurcated into radial, ulnar and common interosseus artery at the level of the neck of the radius (figure 3 ).

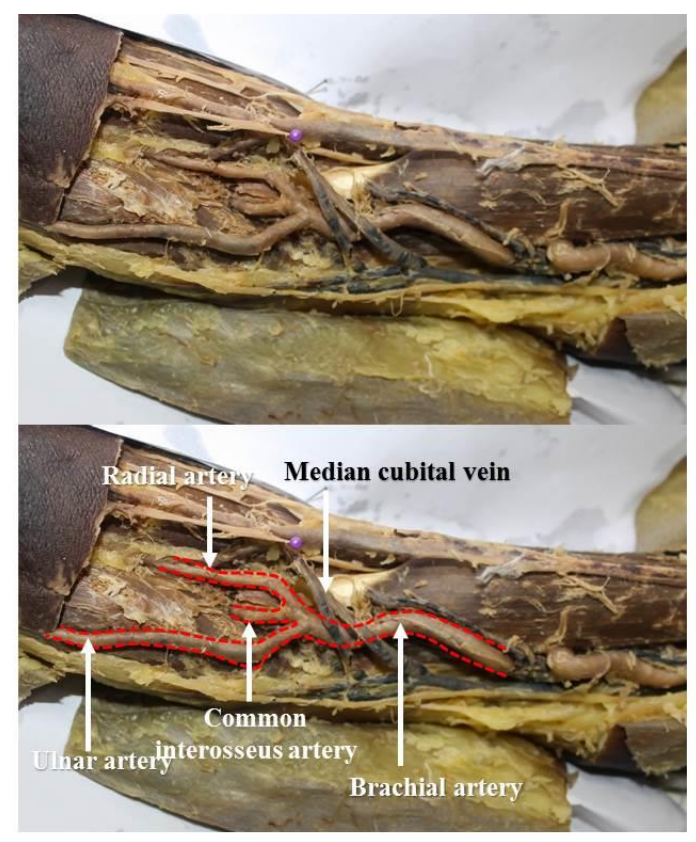

Figure 3: Trifurcation of the brachial artery in the cubital fossa

The radial artery was further traced and found to be of standard description while the ulnar artery continued superficial to the flexor digitorum superficialis and flexor carpi ulnaris up to mid forearm: $7 \mathrm{~cm}$ from trifurcation and then ran deep into the plane between flexor carpi ulnaris and flexor digitorum profundus. The common interosseus artery too ran its usual course superficial ulnar artery was detected in one specimen (1.85\%) (figure 4).

The ulnar artery commenced at the level of the neck of the radius and passed superficial to the pronator teres, fibrous arch of the flexor digitorum superficialis, flexor carpi ulnaris and continued lateral to flexor carpi ulnaris tendon at the distal forearm, just deep to the skin and

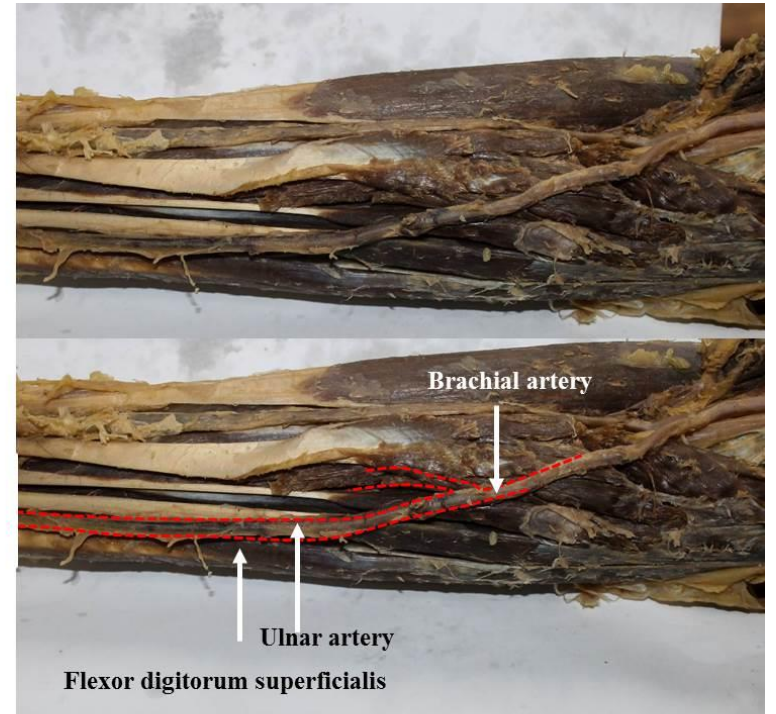

Figure 4: Superficial ulnar artery

the deep facia throughout its course and continued as the superficial palmar arch.

\section{Discussion}

Local hemodynamic factors are said to influence the development of blood vessels during embryological period and alteration of these factors causes anatomical variations in the arterial system (6). Variations were observed in $5.5 \%$ of specimens in our study. Ciervo et al stated that the vascular variations of the upper limb are estimated to be between $9 \%$ to $18.5 \%$ which is consistent with our study (7).

High bifurcation of the brachial artery is estimated to be between $3 \%$ to $15 \%$ (7). The percentage of high bifurcation of the brachial artery in our study was $3.7 \%$ and is consistent with reported studies.

Williams et al had reported that the high bifurcation of the brachial artery is more frequent than trifurcations and if it is a trifurcation, the third artery is the common interosseous artery (8). Huber et al mentioned that the third branch could be median artery, common interosseous artery or the radial recurrent branch (9). However in our study, the percentage of the trifurcation of brachial artery was $1.85 \%$ and the third branch was the common interosseous. 
Senanayake et al presented a rare case of ulnar artery arising from the medial side of the upper brachial artery and descending deep to the deep fascia and superficial to the bicipital aponeurosis (10). De Costa et al stated that the incidence of the superficial ulnar artery is $0.7 \%-7 \%$ (11). It was $1.85 \%$ in our sample similar to these reports.

Clinicians need to be aware of these anatomical variations when diagnosing as well as during therapeutic procedures to avoid unnecessary complications and injuries and therefore timely reporting of such variations is of paramount importance.

Corresponding author: Dr (Mrs.) H.A. Amaratunga

Address: Department of Anatomy, Faculty of Medicine, University of Peradeniya, Peradeniya, 20400, Sri Lanka Email:himanipeiris@yahoo.com, himanip@pdn.ac.lk

Phone: 094812396275 , Mobile: 0773920177 Fax: 094812389106

\section{Acknowledgements}

We would like the thank Mr T.V Wijethunga, $\mathrm{Mr}$ Y.S.M.K.G.B Yallarawa and Miss H.M.D.R Wickramathilaka for assistance in dissecting.

\section{References}

[1] Kosuri KC, Siddaraju KS, Nelliuri V, Ashish S, Neeraj K. Anatomical Variations of Brachial artery-Its Morphology, Embryogenesisi and Clinical Implications. J Clin Diagn Res 2014;8(12) 17-20.

[2] Selda Y, Necdet K, Cenk M. O. Variations associated with high division of the superficial brachial artery. Int $\mathrm{J}$ Anat Var 2014;7:45-47.
[3] Kian K, Shapiro J.A, Salman L, Khan R.A, Merril D, Grarcia L, Eid N, Asif A, Aldahan A, Beathard G. High brachial artey bifurcation: clinical considerations and practical implications for an arteriovenous access. Seminar in Dialysis 2011;25(2):244-247.

[4] Patnik V.V.G, Kalsey G, Singla R.K, Branching pattern of brachial artery- A Morphiological study. J Anat soc Ind 2001;163-165.

[5] Reddi C.K, Syed N.E, Phukon N.A, Dutta $\mathrm{R}$, Bilateral trifurcation of Brachial arteryA case report. Int $\mathrm{J}$ Biol Med Res 2011;2(4):1193-1194.

[6] Arey LB. Developmental anatomy in: Development of the arteries. 6th edition. Philadelphia: W.B. Saunders, 1957: 375377.

[7] Ciervo A, Kahn M, Pangilian AJ, Dardik H. Absence of the brachial artery: Report of a rare human variation and review of upper extremity arterial anomalies. Journal of Vascular Surgery 2001;33: 191-194.

[8] Williams P.L; Bannister, L.H.; Berry,M.M. Colins, P; Dyson, M; Dussek, J.E. and Ferguson, M.W.J.: "Gray's Anatomy”. In: Cardiovascular system. Gabella G Edr. 38th edition. Churchill, Livingstone, New York, 1999:1537-44.

[9] Huber, G.C.: Piersol's Human Anatomy. In : The vascular system. 9thedition. J.B. Lippincott Philadelphia.1930: 767-791.

[10] Senanayake K.J, Salgado S, Rathnayake M.J, Fernando R, Somarathne $\mathrm{K}$, A rare variant of the superficial ulnar artery and its clinical implications: a case report, J Med case reports, 2007;7(1):128.

[11] D'Costa S, Shenoy B. M, Narayana K, The incidence of a superficial arterial pattern in the human upper extremities. Folia Morphol 2004; 63(4); 459-463 